\title{
Impacts of pre- and postnatal nutrition on glucagon regulation and hepatic signalling in sheep
}

\author{
Bishnu Adhikari1,2, Prabhat Khanal1,3,4 and Mette Olaf Nielsen' \\ 1Department of Veterinary and Animal Sciences, Faculty of Health and Medical Sciences, University of Copenhagen, Copenhagen, Denmark \\ 2Department of Poultry Science, University of Arkansas, Fayetteville, Arkansas, USA \\ Institute of Basic Medical Sciences, Faculty of Medicine, The Norwegian Transgenic Centre (NTS), University of Oslo, Oslo, Norway \\ ${ }^{4}$ Faculty of Biosciences and Aquaculture (FBA), Nord University, Steinkjer, Norway \\ Correspondence should be addressed to M O Nielsen: mette.olaf.nielsen@sund.ku.dk
}

\section{Abstract}

To evaluate the long-term impacts of early-life nutritional manipulations on glucagon secretion and hepatic signalling, thirty-six twin-pregnant ewes during their last trimester were exposed to NORM (fulfilling $100 \%$ of daily energy/protein requirements), HIGH (fulfilling 150/110\% of daily energy/protein requirements) or LOW (50\% of NORM) diets. Twin lambs were assigned after birth to a moderate (CONV) or high-carbohydrate highfat (HCHF) diet until 6 months. Then, responses in plasma glucagon concentrations and glucagon ratios relative to previously reported values for insulin, glucose and lactate were determined after intravenous bolus injections of glucose or propionate (fed and 2-day fasting state). Hepatic mRNA expressions of glucagon receptor (GCGR), glucose6-phosphatase (G6PC), phosphoenolpyruvate carboxykinase (PEPCK) and fructose 1,6-biphosphatase $(F B P)$ were also determined in a sub group of autopsied lambs. Expression of GCGR and all three enzymes were supressed by prenatal LOW compared to NORM (except PEPCK) and HIGH (except FBP) nutrition. The postnatal HCHF diet reduced plasma glucagon responses to propionate and hepatic mRNA expression of all genes. In response to propionate, insulin/glucagon ratio was decreased (fasted state), but lactate/glucagon and glucose/glucagon increased in HCHF compared to CONV lambs. In conclusion, prenatal undernutrition and postnatal overnutrition had similar long-term implications and reduced hepatic glucagon signalling. Glucagon secretory responses to propionate were, however, not related to the prenatal nutrition history, but negatively affected by the postnatal obesogenic diet. The pancreatic $\alpha$-cell compared to $\beta$-cells may thus be less sensitive towards late gestation malnutrition, whereas hepatic glucagon signalling appears to be a target of prenatal programming.

\author{
Key Words \\ - glucose tolerance test \\ - propionate tolerance test \\ - foetal programming \\ - hepatic gene expression
}

Journal of Endocrinology (2018) 238, 1-12

\section{Introduction}

Glucagon plays a key role in glucose homeostasis due to its stimulating effect on hepatic glucose output in response to low blood glucose levels (Jiang \& Zhang 2003). In addition, glucagon has also been suggested to be a stimulator of lipolysis in adipose tissue, resulting in liberation of non-esterified fatty acids (NEFA) and glycerol (Vaughan \& Steinberg 1963), but the role of glucagon in the quantitative regulation of lipid metabolism in 
adipose tissues in mammals is still subject to debate. The effects of glucagon are mediated through binding with the specific glucagon receptor (GCGR) that belongs to the superfamily of heptahelical transmembrane $G$ protein-coupled receptors (Jiang et al. 2001). Because of the high similarity in amino acid sequences of glucagon, glicentin and oxyntomodulin, cross-reactivity and non-specificity can occur, when detecting glucagon by assays utilising antisera (Campbell \& Drucker 2015). In addition, various endopeptidases and exopeptidases can convert glucagon into truncated forms, which can show cross-reactivity with some antisera (Bak et al. 2014). Thus, poor specificity and/or suboptimal sensitivity of commercial available assays for glucagon determination have been major problems (Bak et al. 2014) limiting research efforts to obtain greater understanding of the role of this hormone in health and disease. Recently, a commercial sandwich ELISA was developed, which can measure glucagon with high precision, specificity and sensitivity in humans (Albrechtsen et al. 2014) and other animal species (Hall et al. 2015), since the primary structure of the glucagon molecule is conserved among different species (Sundby 1976).

Previously, research on the endocrine pancreas has focused mainly on insulin and the $\beta$-cell, and very little in comparison has been made on glucagon and the $\alpha$-cell in relation to developmental origins of diabetes, obesity and associated metabolic disorders. Thus, the detailed mechanisms of regulation of glucagon secretion and signalling are still elusive. Various factors are responsible for glucagon secretion and regulation, like circulating nutrient metabolites (glucose, amino acids, NEFA, and ketone bodies), neuronal factors (sympathetic and parasympathetic system), hormones, developmental and nutritional factors, etc. (Gerich et al. 1976). Both overnutrition and undernutrition during the gestation period can predispose for development of obesity and metabolic disorders in offspring as reviewed earlier (Taylor et al. 2007). In addition, maternal obesity in pregnant sheep can induce alterations in the pancreatic $\beta$ cell structure and function in their progeny, which predispose for obesity and metabolic diseases (Taylor et al. 2007, Zhang et al. 2011), and obesity-induced hyperglucagonaemia reported in a human study (Manell et al. 2016) may be a further complication. Studies in human, rat and sheep tissue have demonstrated that the number of pancreatic $\beta$ cells is reduced in response to nutrient restriction during foetal life (Reusens \& Remacle 2006).

We have previously reported that exposure to an obesogenic, high-fat diet in early postnatal life resulted in hyperglycaemia and insulin resistance in adolescent lambs with a history of malnutrition in late foetal life (Khanal et al. 2015). This gave rise to the question, whether maternal malnutrition and/or an early postnatal obesogenic diet also affect glucagon secretion and pathways involved in hepatic gluconeogenesis, which potentially could contribute to the development of hyperglycaemia and related disorders in glucose homeostatic regulation. Therefore, we performed a study using the Copenhagen sheep model (Nielsen et al. 2013, Khanal et al. 2014), where we aimed to test the hypothesis that both prenatal and postnatal nutrition manipulations interfere with subsequent secretory responses of the pancreatic $\alpha$-cell to secretagogues (propionate) and inhibitors (glucose), as well as on pathways involved in hepatic gluconeogenesis in sheep.

\section{Materials and methods}

\section{Experimental set-up}

Blood plasma and liver tissue samples, available from a large experiment with the Copenhagen sheep model, formed the basis for this study and allowed us to investigate the impacts of prenatal and postnatal nutrition manipulations on the pancreatic $\alpha$-cell secretory function and hepatic glucagon signalling. All the experimental procedures for the Copenhagen sheep study were approved by the National Committee on Animal Experimentation, Denmark, and the experimental set-up has been described in detail (Khanal et al. 2014). In brief, the study was a $3 \times 2$ factorial design, where 36 twin-pregnant multiparous crossbred Texel ewes during the last 6 weeks of gestation (term $=147$ days) were subjected to one of the three different diets: NORM, LOW or HIGH. The NORM diet fulfilled $100 \%$ of daily energy and protein requirements according to Danish feeding standards, LOW fulfilled $50 \%$ of those requirements and HIGH fulfilled $150 \%$ of energy and $110 \%$ of protein requirements. From 3 days to 6 months of age (just after puberty), one lamb from each twin pair was subjected to an obesogenic, highcarbohydrate-high-fat (HCHF; $N=35,18$ male, 17 female) diet and the other to a moderate conventional (CONV; 16 male, 19 female) diet. The CONV diet consisted of milk replacer supplemented with good-quality hay until 8 weeks of age, and hay only from 8 weeks of age until 6 months of age. The daily provision was adjusted to achieve constant moderate growth rates of $\sim 225 \mathrm{~g}$ /day to ensure a uniform, predominantly lean growth and with 
limited fat deposition in all CONV lambs. The HCHF diet was designed to be an obesogenic diet allowing for excessive fat deposition in HCHF lambs at 6 months of age. It consisted of a 1:1 mix of milk replacer and $38 \%$ fat dairy cream (maximal daily allowance was $2.5 \mathrm{~L}$ ) and rolled maize (maximal daily allowance was $1 \mathrm{~kg}$ ) supplemented with small amounts of barley straw to prevent digestive disorders. Water and a vitamin-mineral mix was available ad libitum throughout the experiment.

\section{Tolerance tests}

Blood samples were available from 6-month-old lambs, which had been subjected to an intravenous glucose tolerance test and two intravenous propionate tolerance tests on separate days, as previously described (Khanal et al. 2015). In the tolerance tests, bolus injections were given via an indwelling catheter in a jugular vein of either $0.45 \mathrm{~g}$ glucose per $\mathrm{kg}$ metabolic body weight (MBW) or $6.25 \mathrm{mmol}$ sodium propionate per $\mathrm{kg} \mathrm{MBW}$. The glucose tolerance test was conducted in the morning after the lambs had been fasted overnight. One propionate tolerance test was conducted approximately $4 \mathrm{~h}$ after the morning feeding, and the other was conducted after the lambs had been fasted for $44 \mathrm{~h}$. Blood samples were collected from indwelling catheters in a jugular vein at $-15,-5,2.5,10$, $20,30,60$ and $120 \mathrm{~min}$ post injection during the glucose tolerance test and at $-5,5,10,15,36,60$ and $120 \mathrm{~min}$ during the propionate tolerance tests. The timing of samplings was scheduled according to the expected time, where peak values of glucose were reached post injection.

\section{Slaughtering of animals and tissue collection}

Liver biopsies were available from 26 six-month-old lambs (all from different twin pairs and from the different experimental treatment groups), which were slaughtered after the tolerance tests, as previously described (Khanal et al. 2014). Tissue samples were obtained from the right lobe of the liver and immediately fixated in RNA later (RNAlater solution, Ambion) for $24 \mathrm{~h}$ and then stored at $-80^{\circ} \mathrm{C}$ pending gene expression analyses.

\section{Glucagon determination}

A commercially available ELISA assay (Mercodia Glucagon ELISA, Mercodia AB, Uppsala, Sweden) was used for the first time to determine glucagon in sheep plasma. Therefore, validation tests were initially conducted using protocols according to the manufacturer's instructions.
All validation results were evaluated by the manufacturer, and performance of the assay for sheep plasma deemed satisfactory. The validation for sheep plasma included dilution, spiking and evaluation of intra- and interassay coefficients of variation for high and low glucagon control samples. Thirty plasma samples previously analysed for insulin (Khanal et al. 2015) and known to have low, medium or high concentrations of insulin were run in the first plate and were found to have high, medium and low glucagon concentrations, respectively. Five samples containing glucagon concentration in the range of $10-72 \mathrm{pmol} / \mathrm{L}$ were analysed undiluted and at twofold dilution with the assay Calibrator 0 solution. The recovery \% after twofold dilution was $89 \pm 6.01 \%$ and not related to the initial concentration.

For the spiking study, five samples with low concentration of glucagon $(1.2-1.8 \mathrm{pmol} / \mathrm{L})$ were mixed with a preparation of purified antigen, using the Calibrator 5 (highest glucagon standard) solution to add known amounts of purified glucagon. Three types of spiked and unspiked samples were produced for this study: (a) spiked plasma samples were produced by adding $20 \mu \mathrm{L}$ purified antigen to $200 \mu \mathrm{L}$ of the low glucagon plasma samples, (b) unspiked, slightly diluted control samples were made by adding $20 \mu \mathrm{L}$ Calibrator 0 (without antigen) to $200 \mu \mathrm{L}$ of the low glucagon plasma samples and (c) a spiked Calibrator 0 sample was produced by adding $20 \mu \mathrm{L}$ of Calibrator 5 to $200 \mu \mathrm{L}$ of the Calibrator 0 solution. The recovery \% during the spiking study was $78 \pm 0.80 \%$.

Calculation of intra- and inter-assay coefficients of variations were performed by analysing pooled high (control 1) and low (control 2) glucagon control samples included in ten different assays (plates). The mean intraassay coefficients of variation were $5.32 \%$ and $7.67 \%$ in control samples 1 and 2, respectively, and the mean interassay coefficient of variations were $9.15 \%$ and $8.22 \%$ in control samples 1 and 2, respectively.

After validation and approval of the performance of the assay with sheep plasma, glucagon analyses were conducted in duplicate on plasma samples separated from blood stabilised with EDTA and stored at $-20^{\circ} \mathrm{C}$ until analysed.

\section{Quantitative reverse transcription PCR}

The mRNA extraction, cDNA synthesis and quantification of the mRNA expression levels of target genes (glucagon receptor (GCGR), glucose-6-phosphatase (G6PC), phosphoenolpyruvate carboxykinase (PEPCK), and fructose 1,6-biphosphatase $(F B P))$ in liver tissue were 


\begin{tabular}{|c|c|c|c|c|}
\hline $\begin{array}{l}\text { Journal of } \\
\text { Endocrinology }\end{array}$ & B Adhikari et al. & $\begin{array}{l}\text { Prenatal and postnatal nutrition } \\
\text { and glucagon regulation }\end{array}$ & 238:1 & 4 \\
\hline
\end{tabular}

performed as previously described (Hou et al. 2013). An ovine primer for the GCGR was designed by Primer3Plus (http://primer3plus.com/cgi-bin/dev/primer3plus.cgi) using a reported gene sequence of GCGR of sheep (http:// www.ncbi.nlm.nih.gov), whereas the primer sequences of other genes were taken from already published papers, as shown in Table 1. A seven-point standard curve was made to determine the efficiency of primers. The efficiency of primers was between 1.76 and 1.90 (this equals an increase between $76 \%$ and $90 \%$ of target nucleic acid in each amplification cycle), as shown in Table 1 . The amplification cycle of qPCR included: denaturation $\left(95^{\circ} \mathrm{C}\right.$ for $\left.10 \mathrm{~s}\right)$, annealing $\left(58-60^{\circ} \mathrm{C}\right.$ for $10 \mathrm{~s})$ and elongation $\left(72^{\circ} \mathrm{C}\right.$ for $\left.20 \mathrm{~s}\right)$ and repeated 45 times in each qPCR reaction. Beta-actin was used as a reference gene to normalise the expression levels of target genes. Data were analysed in Light Cycler 480 instrument ver. 2.0 software using the advanced relative quantification method.

\section{Statistical analysis}

The statistical analyses of data were performed by the SAS software ver. 9.4 (2013, SAS Institute) using the GLIMMIX procedure as described earlier (Khanal et al. 2015). For gene expression data, the model included fixed effects of ewe diet (prenatal diet), lamb diet (postnatal diet), sex and their interaction effects. The model also included ewe body weight, ewe BCS and lamb birth weight as covariates. For tolerance test data, the model furthermore included fixed effect of time of blood sampling, random effects of the individual ewe and lamb within each feeding treatment and repeated measurements of samples within lambs. Models were reduced by backward reductions, where the least significant factors were removed consecutively. Tukey's multiple comparison test was performed to compare difference in least squares means (LSM), and the results were presented as LSM with standard error of the mean (LSM \pm s.E.M.). The significant level was set at $P<0.05$. Previously reported data (Khanal et al. 2015) for plasma profiles of insulin, glucose and lactate during the glucose and propionate tolerance tests in the same lambs in the same experiment were used to calculate ratios between those metabolites and insulin relative to glucagon. These ratios were analysed by the same statistical procedure described earlier.

\section{Results}

There were no effects of sex on any of the measured parameters in this experiment or the calculated plasma

\footnotetext{
http://joe.endocrinology-journals.org
} https://doi.org/10.1530/JOE-17-0705

() 2018 Society for Endocrinology Published by Bioscientifica Ltd. Printed in Great Britain
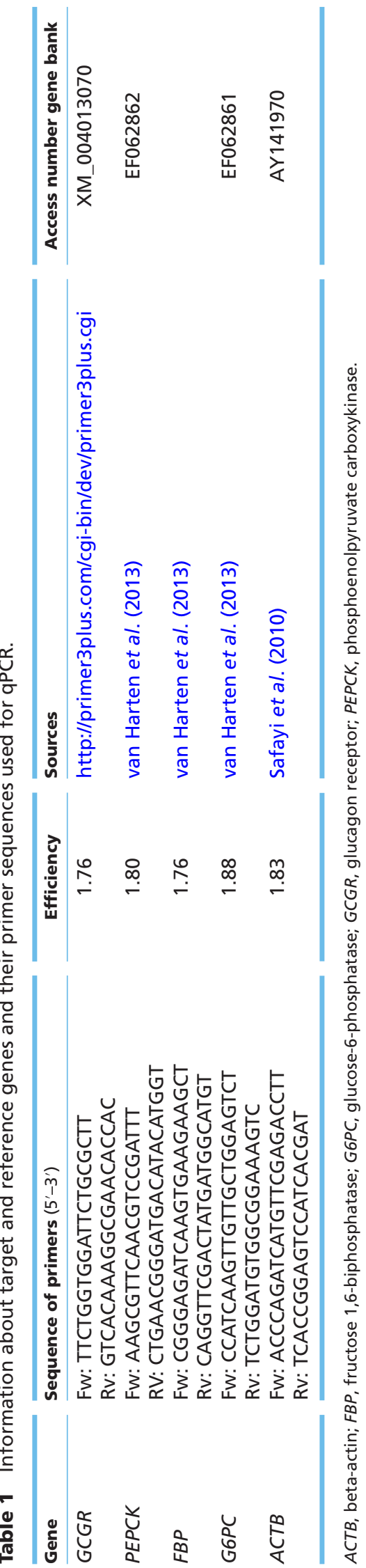


\begin{tabular}{|l|l|l|l|l|}
$\begin{array}{l}\text { Journal of } \\
\text { Endocrinology }\end{array}$ & B Adhikari et al. & $\begin{array}{l}\text { Prenatal and postnatal nutrition } \\
\text { and glucagon regulation }\end{array}$ & $\mathbf{2 3 8 : 1}$ & $\mathbf{5}$ \\
\hline
\end{tabular}

concentrations ratios, unless explicitly stated in the following sections.

\section{Changes in plasma glucagon during in vivo tolerance tests}

Table 2 provides an overview of observed peak (or nadir) plasma glucagon concentrations determined in the different tolerance tests and the time points (in minutes), where peak/nadir values were reached post injection for plasma glucagon. Table 2 furthermore provides an extract of selected previously reported values for glucose, insulin and lactate determined in the same animals in the same experiment and in the same tolerance tests (Khanal et al. 2015). These data have been included to be able to evaluate, whether changes in glucagon secretory function relating to early life nutrition may have contributed to the previously reported changes in glucose homeostasis in the lambs.

\section{Propionate tolerance tests (after $44 \mathrm{~h}$ of fasting and in the fed state)}

The general patterns of change in glucagon concentrations, insulin/glucagon, glucose/glucagon and lactate/glucagon ratios were similar, whether propionate tolerance tests were conducted in the fed state or after $44 \mathrm{~h}$ of fasting (Figs 1 and 2). There were no significant effects of prenatal nutrition at any time points during propionate tolerance tests in the fed or fasted state on glucagon, insulin/ glucagon, glucose/glucagon or lactate/glucagon ratios. But the postnatal lamb diet significantly affected changes in these parameters $(P<0.05$ for lamb diet and lamb diet *time interaction) as described in the following.

Intravenous injection of propionate-induced dramatic and transient increases in plasma glucagon in all lambs with peak values observed $10 \mathrm{~min}$ post injection, except in CONV lambs in the fed state, where the occurrence of the peak occurred already 5 min post injection (Figs $1 \mathrm{~A}$ and 2A). Peak values were around 34- (CONV) and 16(HCHF) fold higher than pre-injection values in the fasted state, as compared to only around 6- (CONV) and 7- (HCHF) fold higher in the fed state (Figs 1A, 2A and Table 2). After peak values had been reached, glucagon concentrations returned to pre-injection levels by 36 (fed state) to 60 (fasted state) min post injection (Figs $1 \mathrm{~A}$ and $2 \mathrm{~A}$ ). As can be seen in Figs $1 \mathrm{~A}$ and $2 \mathrm{~A}$, CONV lambs reached peak values of glucagon that were around 3-fold higher than the peak values observed in HCHF lambs $(P<0.0001)$. The peak glucagon concentrations were lower (appr. 45 and 57\% reduction in CONV and HCHF lambs, http://joe.endocrinology-journals.org

https://doi.org/10.1530/JOE-17-0705
๑ 2018 Society for Endocrinology Published by Bioscientifica Ltd.

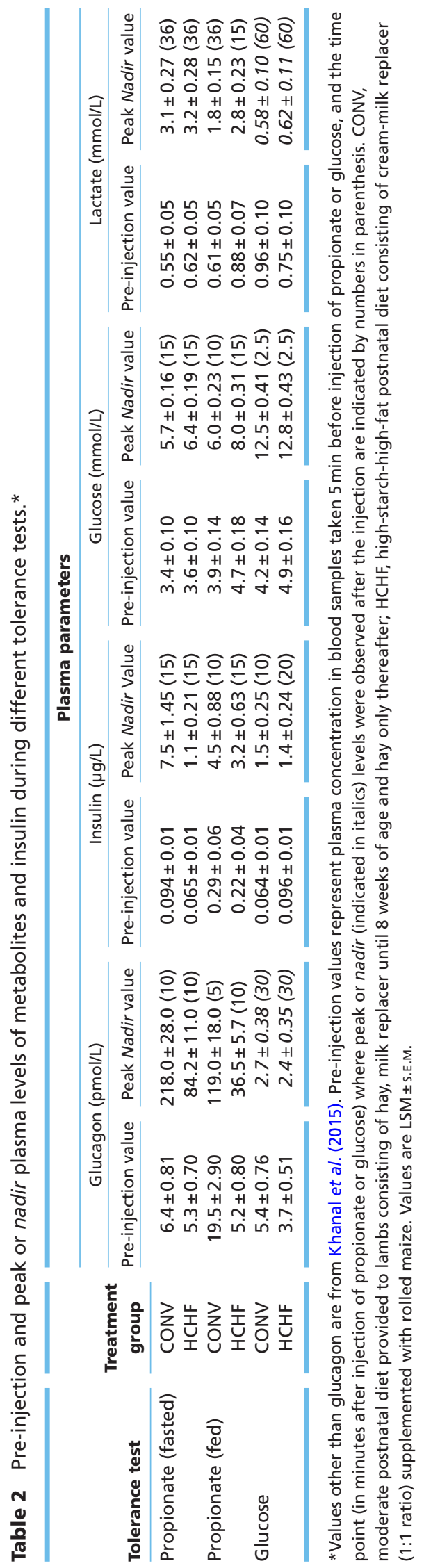


Propionate tolerance test (fasted)
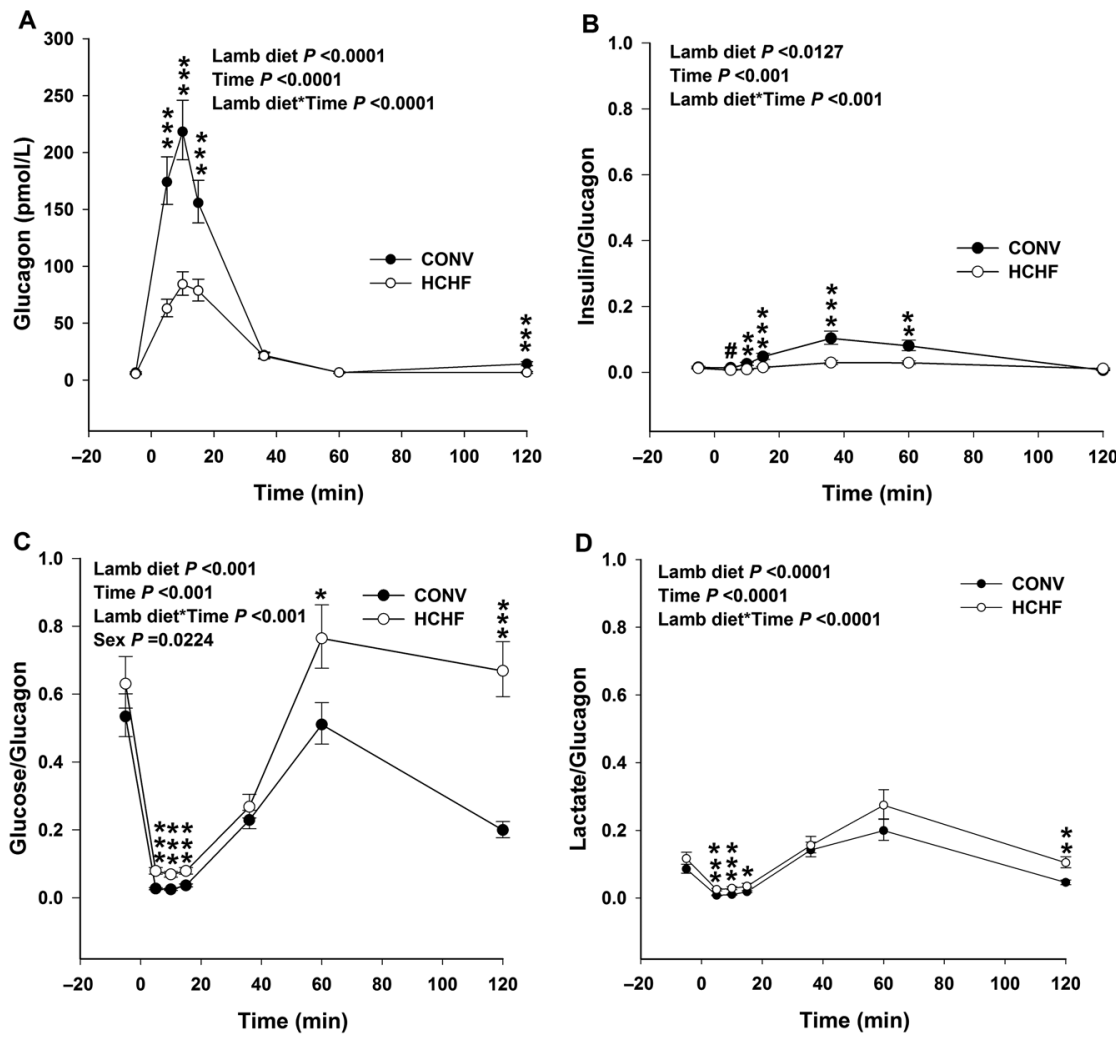

Figure 1

Impact of an obesogenic, high-fat postnatal diet on changes in plasma glucagon concentrations $(\mathrm{pmol} / \mathrm{L})(\mathrm{A})$ and plasma ratios of insulin/glucagon (B), glucose/glucagon (C) and lactate/glucagon (D) in 6-month-old 44-h fasted lambs after an intravenous injection of sodium propionate $(2.5 \mathrm{M}$ in sterile water (Silkeborg Pharmacy, Silkeborg, Denmark), $2.5 \mathrm{~mL} / \mathrm{kg}^{0.75} ; 6.25 \mathrm{mmol}$ sodium propionate $\mathrm{kg}^{-0.75}$ in saline). CONV and HCHF: see legend to Table 2. Values are least squares means \pm s. E.M. represented by vertical bars. The effects were significant at $* * * P<0.0001$, $* * P<0.001, * P<0.01$, and ${ }^{*} P<0.05$.

\section{Propionate tolerance test (fed)}
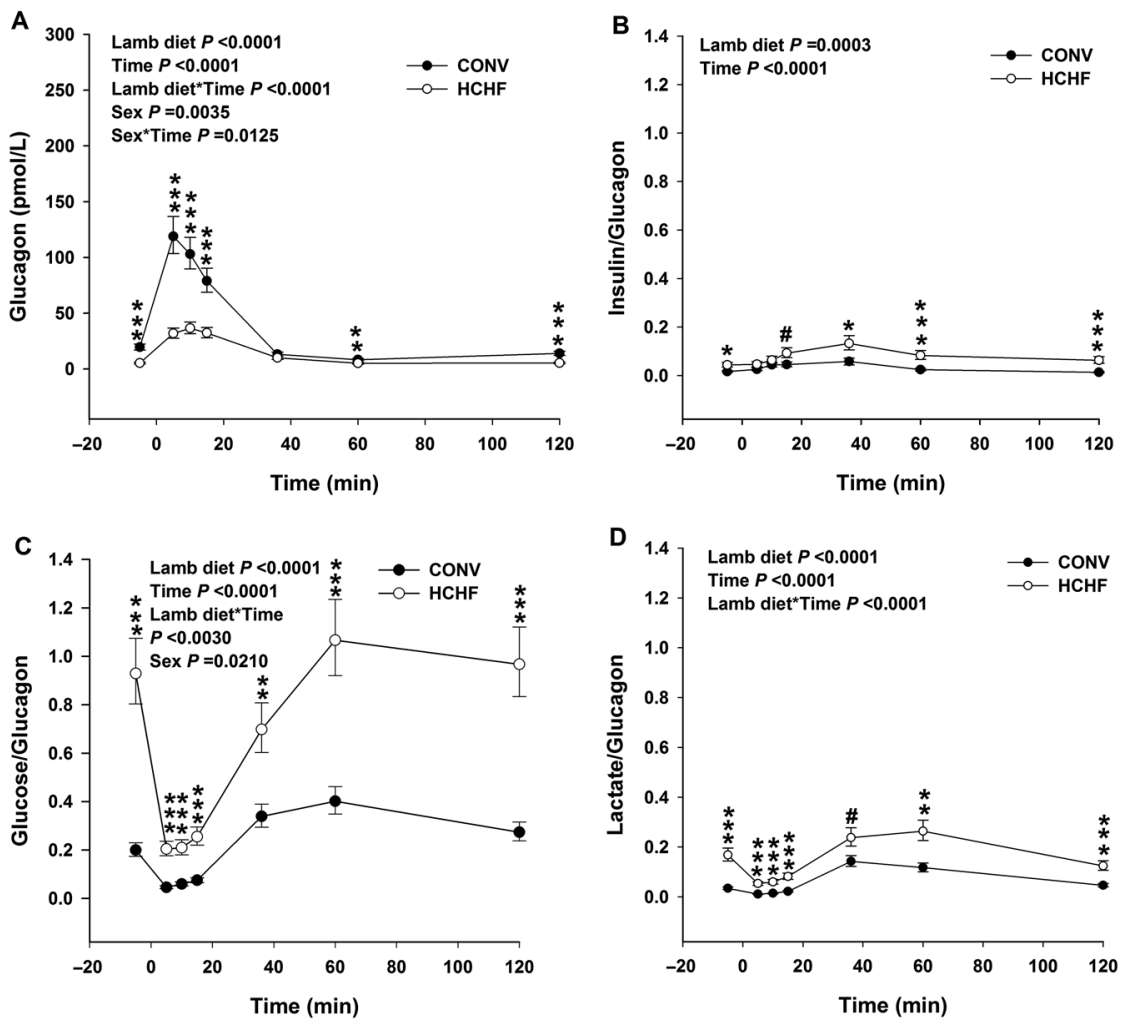

Figure 2

Impact of an obesogenic, high-fat postnatal diet on changes in plasma glucagon concentrations (pmol/L) (A) and plasma ratios of insulin/glucagon (B), glucose/glucagon (C) and lactate/glucagon (D) in 6-month-old lambs in the fed state after an intravenous injection of sodium propionate $(2.5 \mathrm{M}$ in sterile water (Silkeborg Pharmacy), $2.5 \mathrm{~mL}$ $\mathrm{kg}^{0.75} ; 6.25 \mathrm{mmol}$ sodium propionate $\mathrm{kg}^{-0.75}$ in saline). CONV and HCHF: see legend to Table 2. Values are least squares means \pm S.E.M. represented by vertical bars. $* * *, * *, *$, and $\#$ : see legend to Fig. 1. 
respectively; Table 2), when the propionate tolerance test was conducted in the fed as compared to the fasted state. HCHF lambs (fed and fasted states) and CONV lambs in fasted state had similar pre-injection levels of glucagon, but these levels were markedly higher in CONV lambs in fed state (Table 2).

In the fed state, females had significantly higher plasma glucagon levels than male lambs $(P=0.0035)$, and in female lambs, glucagon increased to higher levels at 5 ( $P=0.0005), 10(P=0.0228)$ and $15(P=0.0008)$ minutes post injection than in male lambs (results not shown).

Plasma insulin/glucagon ratios increased gradually from 5 to $36 \mathrm{~min}$ after propionate injection in the fasted (Fig. 1B) as well as fed (Fig. 2B) state, since peak levels were reached later for insulin (10 and $15 \mathrm{~min}$ in fed and fasted states, respectively; Khanal et al. 2015) than glucagon (5 or $10 \mathrm{~min}$ in fed and fasted states, respectively), and plasma levels of insulin also remained elevated for a longer time post-peak than glucagon. Due to proportionately lower responses in glucagon compared to insulin, insulin/ glucagon ratios were consistently higher in HCHF than CONV lambs in the fed state (Fig. 2B). However, in the fasted state, insulin secretory responses to propionate were suppressed even more markedly in HCHF lambs than glucagon, and insulin/glucagon ratios therefore increased by $36 \mathrm{~min}$ post injection to 3 -fold higher levels in the fasted CONV compared to HCHF lambs $(P<0.0001$; Fig. 1B).

Glucose/glucagon (Figs 1C and 2C) and lactate/ glucagon (Figs 1D and 2D) concentration ratios decreased abruptly to very low levels within 5 min after injection and remained at this low level until $15 \mathrm{~min}$ post injection. Thereafter, the ratios gradually increased and returned to pre-injection levels within $60 \mathrm{~min}$ post injection. CONV lambs had consistently lower glucose/glucagon and lactate/glucagon ratios compared to HCHF lambs $(P<0.0001)$, particularly in the fed state, reflecting the proportionately much more dramatic changes in glucagon compared to glucose and lactate (Table 2).

\section{Glucose tolerance test}

Glucose injection in overnight fasted lambs depressed glucagon levels in all groups and minimal values were reached $30 \mathrm{~min}$ post injection, as shown in Fig. 3A. The changes in glucagon levels post injection depended on the prenatal nutrition in a gender-specific way, since NORM and LOW female lambs had numerically higher glucagon levels as compared to NORM, HIGH and LOW males at alltime points. The difference was only significant, however, between LOW females and NORM males at 120 min post
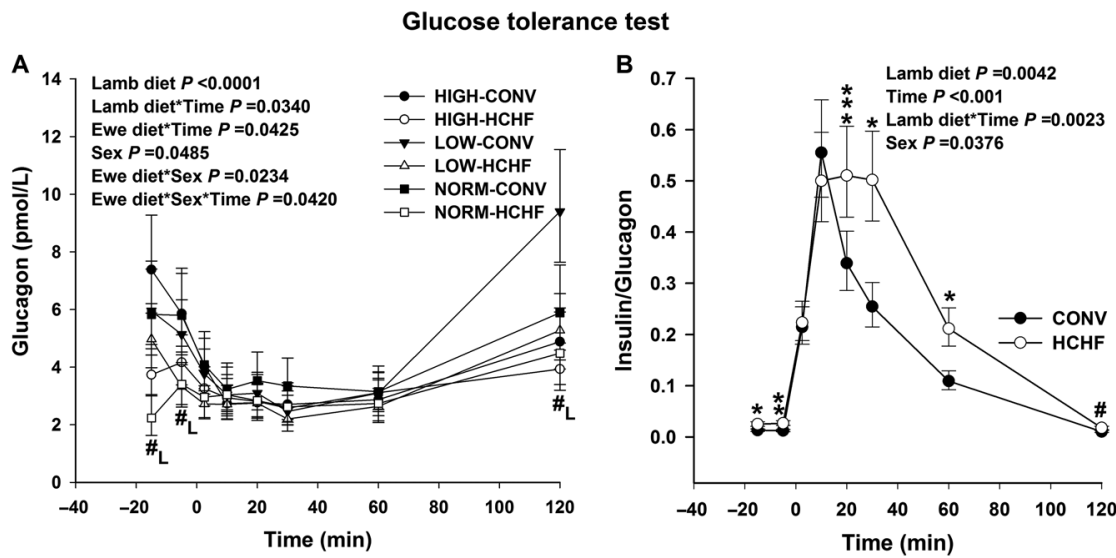

Figure 3

Impact of prenatal overnutrition and undernutrition and a postnatal obesogenic, high-fat diet on changes in plasma glucagon concentrations (pmol/L) (A) and plasma ratios of insulin/glucagon (B), glucose/glucagon (C), and lactate/glucagon (D) in 6-month-old overnight fasted lambs after an intravenous injection of $0.45 \mathrm{~g} / \mathrm{kg}^{0.75}$ glucose $(0.5 \mathrm{~g} / \mathrm{mL}$ in sterile water, SAD, Copenhagen, Denmark). HIGH, lambs born by ewes receiving a diet providing $150 \%$ of daily energy and $110 \%$ of daily protein requirements; LOW, lambs born by ewes receiving a diet providing $50 \%$ of daily energy and protein requirements; NORM, lambs born by ewes receiving a diet fulfilling $100 \%$ of the daily energy and protein requirements; CONV and HCHF: see legend to Table 2. Values are least squares means \pm S.E.M. represented by vertical bars. \# $L$ represents significant effect of lamb diet at $P<0.05$. 
injection $(P<0.05)$ (results not shown). Apart from that, it was difficult to discern any systematic impact of the prenatal diet on the changes in glucagon levels prior to or after glucose injection (Fig. 3A).

The postnatal diet had a systematic impact on changes in glucagon levels before and after glucose injection, where CONV lambs had significantly higher glucagon levels than HCHF lambs prior to injection $(-15$ and -5 , $P<0.05)$ and by $120 \mathrm{~min}$ post injection $(P<0.05)$. The glucagon levels were depressed more by glucose in CONV than HCHF lambs, thus all groups reached the same low plasma glucagon level from 2.5 to $60 \mathrm{~min}$ post injection (Fig. 3A).

Insulin/glucagon (Fig. 3B) and glucose/glucagon (Fig. 3C) plasma concentration ratios were increased several folds after the glucose injection in all lambs, due to increases in insulin and glucose in contrast to the depression of glucagon levels (Table 2). Sharp peaks for these ratios were reached $10 \mathrm{~min}$ post injection. Thereafter, the ratios gradually returned to pre-injection values by 120 min post injection. The only exception to this pattern was in HCHF lambs, where insulin/glucagon ratio were sustained at peak values for an extended period of time (from 10 to $30 \mathrm{~min}$ post injection; Fig. 3B) reflecting their insulin secretory response (Khanal et al. 2015). HCHF lambs also had higher pre-injection levels for the insulin/ glucagon and glucose/glucagon ratios than CONV lambs $(P<0.01$; Fig. 3B and C).

The lactate/glucagon concentration ratio was also increased after glucose injection, with peak values observed 10 and $20 \mathrm{~min}$ post injection in HCHF and CONV, respectively, and following the increases in lactate after glucose injection (Khanal et al. 2015). HCHF lambs had consistently higher levels of lactate/glucagon ratios than CONV lambs before as well as $2.5(P<0.05)$ and 120 $(P<0.01)$ minutes post injection (Fig. 3D).

Insulin/glucagon and glucose/glucagon ratios were significantly higher in males as compared to females (results not shown; $P<0.05$ ).

\section{Changes in hepatic mRNA expression levels}

\section{GCGR and G6PC}

The mRNA expression levels for the GCGR and G6PC in the liver depended on the combination of prenatal and postnatal nutrition exposure $(P<0.05)$. NORM and HIGH lambs had similar expressions of both of these genes, and expressions were markedly reduced in NORM (only significant for GCGR) and HIGH lambs, when they were fed the HCHF as compared to CONV diet in postnatal life
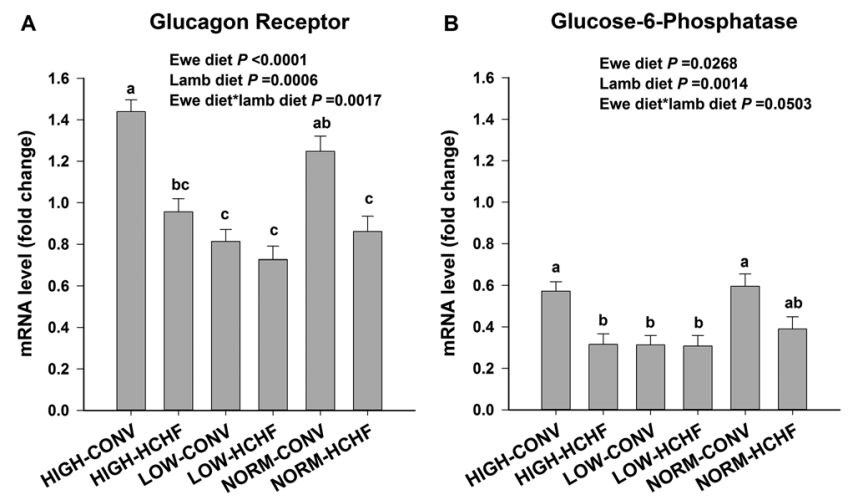

Figure 4

Hepatic mRNA expression levels of the glucagon receptor (A) and glucose-6-phosphatase (B) in 6-month-old lambs depending on the prenatal and postnatal nutrition exposures. Different letters indicate significantly different expression levels among groups. HIGH, LOW, NORM: see legend to Fig. 3, CONV and HCHF: see legend to Table 2.

(Fig. 4A and B). LOW-CONV lambs, however, had as low expressions of the two genes as the NORM-HCHF and HIGH-HCHF lambs, and in LOW lambs, the expressions were not further suppressed upon exposure to the HCHF diet in postnatal life (Fig. 4A and B).

\section{PEPCK and $F B P$}

For PEPCK and $F B P$, the hepatic mRNA expressions were independently affected by the prenatal $(P<0.05)$ and postnatal $(P<0.001)$ nutrition, as shown in Fig. 5A, B, C and D. LOW lambs had lower mRNA expression levels of both PEPCK and FBP as compared to HIGH and NORM lambs. However, the differences were only significant between LOW and HIGH lambs for PEPCK $(P=0.0425)$ and between LOW and NORM lambs for FBP $(P=0.0320)$ (Fig. 5A and C, respectively).

HCHF lambs had markedly reduced expression levels of both PEPCK $(P<0.0001$; Fig. $5 B)$ and FBP $(P=0.0002$; Fig. 5D) compared to CONV lambs.

\section{Discussion}

There are remarkably few studies on plasticity of the pancreatic $\alpha$-cell and glucagon signalling compared to insulin and the pancreatic $\beta$-cell. Hardly any previous studies have addressed the question, how does foetal nutrition impact on glucagon regulation in postnatal life? This was the aim of the present study. To our knowledge, we are the first to present evidence suggesting that an obesogenic diet in early postnatal life has implications for hepatic glucagon signalling in a way which depends 

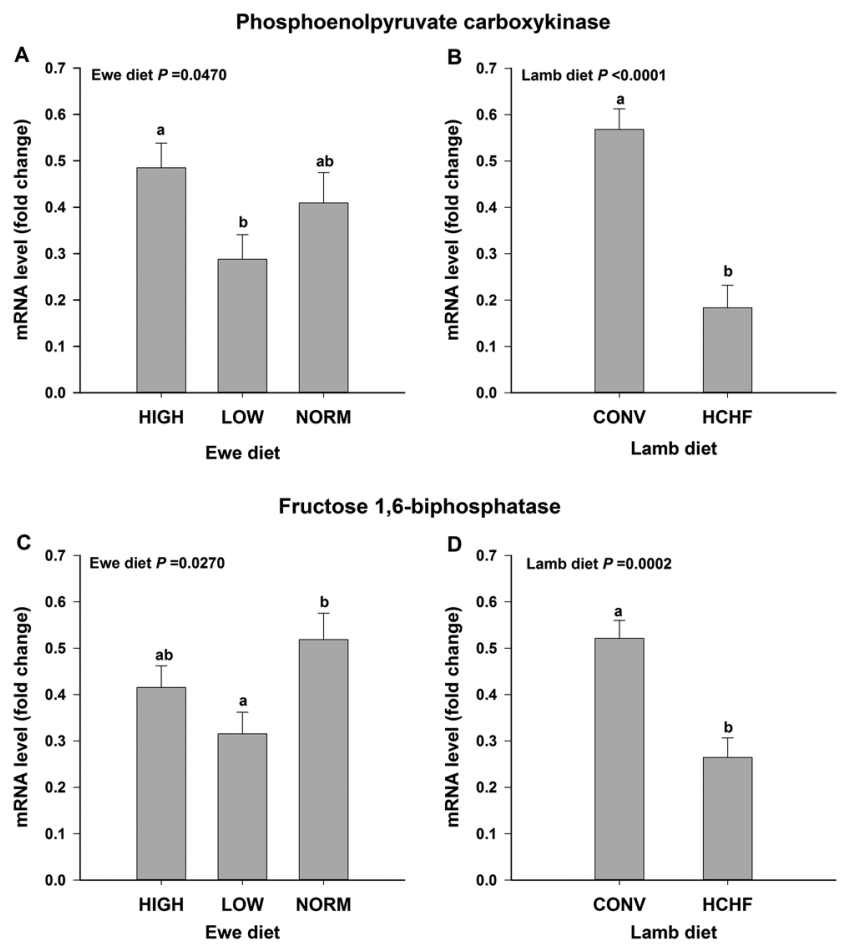

Figure 5

Hepatic mRNA expression levels of phosphoenolpyruvate carboxykinase ( $A$; impact of prenatal nutrition, $B$; impact of postnatal nutrition) and fructose 1,6-biphosphatase ( $C$; impact of prenatal nutrition, $D$; impact of postnatal nutrition) in 6-month-old lambs. Different letters indicate significantly different expression levels between pre- or postnatal treatments. HIGH, LOW, NORM: see legend to Fig. 3, CONV and HCHF: see legend to Table 2.

on the nutrition history in late foetal life. However, we found no evidence to suggest that secretory plasticity of the pancreatic $\alpha$-cell (in contrast to the $\beta$-cell), should be related to the nutrition history in late foetal life, whereas intake of an obesogenic, high-fat diet in early postnatal life had a marked impact on glucagon secretory responses.

\section{Late gestation prenatal undernutrition and an early postnatal obesogenic diet downregulates glucagon signalling in the liver}

Glucagon mediates its action by binding to its specific GCGR (Jiang et al. 2001). Although the GCGR is found in many different tissues (Hansen et al. 1995), glucagon binding occurs mainly to GCGR in the liver (Watanabe et al. 1998), which is the major target organ for glucagon. Glucagon increases hepatic glucose output through stimulation of gluconeogenesis, glycogenolysis and by inhibiting glycogenesis and glycolysis. Glucagon stimulates gluconeogenesis mainly through upregulation of the key enzymes; PEPCK, G6PC and FBP (Kurland \& Pilkis
1995, Quesada et al. 2008). PEPCK converts oxaloacetate into phosphoenolpyruvate, which is the rate-limiting step of gluconeogenesis for substrates entering via the citric acid cycle (Kurland \& Pilkis 1995). FBP facilitates gluconeogenesis from all substrates, including those entering the gluconeogenetic pathways via intermediates in the upper part of the glycolytic pathway, by converting fructose 1,6-biphosphate to fructose-6-phosphate (Kurland \& Pilkis 1995). G6PC catalyses the final step of gluconeogenesis, where free glucose is released from glucose-6-phophate (Jia et al. 2012).

The present study showed that exposure to either foetal undernutrition (LOW) or an obesogenic diet (HCHF) postnatally depressed expression of the hepatic $G C G R$ and key enzymes in several rate-limiting steps of gluconeogenesis (G6PC, PEPCK and FBP). The LOWHCHF early nutrition combination depressed expression of hepatic GCGR and gluconeogenic enzymes by $42-74 \%$ in individual lambs relative to the expression in NORMCONV lambs (data not shown). The finding that expression of the gluconeogenetic enzymes changed in the same direction as that of the GCGR upon exposure to foetal undernutrition or a postnatal high-carbohydrate-highfat diet may be indicative of an association to glucagon signalling and agrees with the observed lower basal glucagon levels in HCHF compared to CONV lambs. It should be borne in mind that the studied hepatic enzymes are influenced by other factors as well, such as insulin and glucocorticoids (Sutherland et al. 1996, Barthel et al. 2003), hepatic supply of key nutrients like long-chain fatty acids and glucose (Marks 1972, Franklin et al. 2005) and affected by pathological conditions like fatty liver (Rukkwamsuk et al. 1999). However, the prenatal nutrition history had no impact on the pre-injection levels of glucose or insulin in any of the tolerance tests in this experiment (Table 2; Khanal et al. 2015), and lambs exposed to the HCHF diet postnatally had opposite secretory responses of glucagon compared to insulin during the glucose (sustained secretory response for a longer period of time) and propionate tolerance tests in the fasted state (markedly reduced insulin response) (Khanal et al. 2015). This suggests that insulin is unlikely to be responsible for the observed differences in hepatic expression of genes encoding for these enzymes. In any case, it is reasonable to assume that a reduced hepatic glucagon signalling via the GCGR receptor can be potentiated by a reduced mRNA expression for gluconeogenetic enzymes to reduce the gluconeogenetic capacity in lambs exposed to undernutrition in late gestation and/or an obesogenic, high-fat diet in postnatal life. 
Although we did not determine gluconeogenetic capacity in the lambs directly, there were other observations pointing in a similar direction. Thus, as previously reported, lactate responses during the propionate tolerance test in fasted lambs were found to be lower in LOW than in NORM and HIGH lambs, and this could not be ascribed to changes in glucose or insulin responses during this tolerance test (Khanal et al. 2015). In addition, HCHF lambs had higher pre-injection levels of lactate and also responded with higher increases in lactate in response to propionate in the fed state. These changes in lactate during the propionate tolerance tests were, as previously discussed, most likely of hepatic origin (Khanal et al. 2015). If this is indeed the case, our findings jointly indicate a reduced ability in LOW and HCHF lambs to run gluconeogenetic pathways to completion, resulting in a shunting (and release) of a larger proportion of carbon into the intermediary product lactate rather than into glucose.

A previous assumption that hepatic glucagon signalling could be a contributing factor to the development of hyperglycaemia observed in the HCHF lambs in the present experiment (Khanal et al. 2015) must therefore be rejected. HCHF lambs had reduced GCGR expression and reduced gene expression of key gluconeogenetic enzymes as already mentioned, which in fact would be working in a direction that would counteract the development of hyperglycaemia.

\section{A postnatal obesogenic, high-fat diet decreases glucagon secretory responses in adolescent lambs}

To our knowledge, the interactive effects of malnutrition exposures in late gestation and early postnatal life have not previously been studied. Secretory responses of the pancreatic $\alpha$-cell to propionate were severely suppressed in lambs exposed to an obesogenic, high-fat diet, but not influenced by the prenatal nutrition history. Propionate, an end product of rumen fermentation and an important gluconeogenic substrate reaching the liver, has previously been reported to be a potent secretagogue of insulin in ruminants (Khanal et al. 2015), and we have further confirmed previous findings that it is also a very potent glucagon secretagogue in ruminants (Sano et al. 1999). The secretory responses to propionate were particularly pronounced, when lambs were in a fasted condition. Hyperglycaemia is an inhibitor of glucagon secretion (Marks 1972) and the inhibition of glucagon secretion is either through paracrine signalling (Franklin et al. 2005, Olsen et al. 2005) or through direct action (MacDonald et al. 2007). This may explain why plasma glucagon levels dropped to low levels after glucose injection and only started to rise again 1 hour after the injection in all groups.

There were similarities in the way glucagon and insulin secretory patterns during the tolerance tests were affected by the prenatal and postnatal nutrition. As mentioned, the HCHF diet severely suppressed secretory responses of glucagon to propionate, and glucagon responses were lower in the fed compared to the fasted state, which was also observed for insulin (Table 2; Khanal et al. 2015). However, the insulin secretory responses to propionate were almost abolished in HCHF lambs when fasted (Khanal et al. 2015), and this was not the case for glucagon. Thus, the secretory function of the pancreatic $\alpha$-cell appears to be less sensitive to the adverse outcomes of a postnatal obesogenic diet compared to the $\beta$-cell.

Reduction in pancreatic growth and $\beta$-cell numbers was reported in late gestation of ewes as a result of over nutrition during pregnancy (Reusens \& Remacle 2006), but our results strongly suggest that the secretory function of the pancreatic $\alpha$-cell is not sensitive towards nutritional manipulations in late gestation. This is in contrast to findings in Japanese macaques, where a decreased $\alpha$-cell mass has been found in offspring born from mothers fed with a high-fat diet during pregnancy (Comstock et al. 2013). Species differences may account for these conflicting observations, since only trace amounts of fatty acids can be transferred across the placenta in ruminants (Elphick et al. 1979) in contrast to primates.

It is the insulin/glucagon plasma ratios rather than concentrations of the individual hormones, which control the rate of multiple enzymatic steps of hepatic metabolism related to glucose release (Unger 1971, Quesada et al. 2008). During the different tolerance tests, we could not find any evidence to suggest that development of hyperglycaemia and associated disorders upon exposure to malnutrition in late foetal or early postnatal life could be related to hyperglucagonemia or changes in the insulin/glucagon ratio.

It was not surprising that glucagon concentrations were higher in CONV than HCHF lambs in the fed or overnight fasted state, due to their differences in substrate supply from forestomach fermentation (much more propionate absorbed from CONV lambs) and small intestinal absorption (more glucose absorbed from HCHF lambs due to the feeding with maize starch, which due to low degradability in the rumen contribute to glucose absorption from starch digestion in the small intestine in addition to glucose absorption from lactose in the milk). However, we were surprised to see that glucagon levels 
were depressed during fasting, when blood glucose levels were depressed. We have no explanation for that, unless glucose has far less importance for regulation of glucagon secretion in ruminants than the decrease in absorption of propionate during fasting. In vitro studies focusing on functions of the sheep pancreas are needed to unravel such aspects of glucagon secretion regulation in ruminant animals, which must clearly be very different from that of monogastrics. Further studies are needed to evaluate, whether there are (patho-) physiological consequences of higher plasma glucagon, lower insulin/glucagon levels and higher glucagon secretory responses in females compared to males.

\section{Conclusion}

Secretory function of the pancreatic $\alpha$-cell, in contrast to the pancreatic $\beta$-cell, does not appear to be a target of nutritional programming in late foetal life in sheep. Implications of gender differences in glucagon secretory patterns remain to be established. Propionate was found to be an almost as potent secretagogue for glucagon as for insulin in adolescent lambs, but glucagon secretory responses were markedly suppressed upon exposure to an obesogenic diet in early postnatal life. The pancreatic $\alpha$-cell appears to be less sensitive to the adverse outcomes of such an obesogenic diet compared to the $\beta$-cell. Hepatic glucagon signalling and gluconeogenetic capacity was reduced upon exposure to undernutrition (but not overnutrition) in late foetal life or an obesogenic diet in early postnatal life, as evidenced by reduced expression of genes encoding for the GCGR and key gluconeogenetic enzymes. Neither changes in glucagon secretory function nor hepatic glucagon signalling or gluconeogenetic capacity could be linked to an obesogenic diet induced hyperglycaemia. On the contrary, adaptations in glucagon secretion and action may play a counteracting effect in this respect.

\section{Declaration of interest}

The authors declare that there is no conflict of interest that could be perceived as prejudicing the impartiality of the research reported.

\section{Funding}

This study was conducted as a part of the Centre for Foetal Programming (CFP), Denmark which was supported by the Danish Council for Strategic Research (grant 09-067124).

\section{References}

Albrechtsen NJW, Hartmann B, Veedfald S, Windeløv JA, Plamboeck A, Bojsen-Møller KN, Idorn T, Feldt-Rasmussen B, Knop FK \& Vilsbøll T 2014 Hyperglucagonaemia analysed by glucagon sandwich ELISA: nonspecific interference or truly elevated levels? Diabetologia 57 1919-1926. (https://doi.org/10.1007/s00125-0143283-z)

Bak MJ, Albrechtsen NW, Pedersen J, Hartmann B, Christensen M, Vilsboll T, Knop FK, Deacon CF, Dragsted LO \& Holst JJ 2014 Specificity and sensitivity of commercially available assays for glucagon and oxyntomodulin measurement in humans. European Journal of Endocrinology 170 529-538. (https://doi.org/10.1530/EJE13-0941)

Barthel A, Scherbaum WA \& Bornstein SR 2003 Novel aspects in the mechanisms of steroid diabetes and the regulation of hepatic glucose production by insulin and steroids. Medizinische Klinik 98 283-286. (https://doi.org/10.1007/s00063-003-1258-9)

Campbell JE \& Drucker DJ 2015 Islet $\alpha$ cells and glucagon - critical regulators of energy homeostasis. Nature Reviews Endocrinology 11 329-338. (https://doi.org/10.1038/nrendo.2015.51)

Comstock SM, Pound LD, Bishop JM, Takahashi DL, Kostrba AM, Smith MS \& Grove KL 2013 High-fat diet consumption during pregnancy and the early post-natal period leads to decreased a cell plasticity in the nonhuman primate. Molecular Metabolism 2 10-22. (https://doi.org/10.1016/j.molmet.2012.11.001)

Elphick MC, Hull D \& Broughton Pipkin F 1979 The transfer of fatty acids across the sheep placenta. Journal of Developmental Physiology 1 31-45.

Franklin I, Gromada J, Gjinovci A, Theander S \& Wollheim CB 2005 Betacell secretory products activate alpha-cell ATP-dependent potassium channels to inhibit glucagon release. Diabetes 54 1808-1815. (https:// doi.org/10.2337/diabetes.54.6.1808)

Gerich JE, Charles MA \& Grodsky GM 1976 Regulation of pancreatic insulin and glucagon secretion. Annual Review of Physiology 38 353-388. (https://doi.org/10.1146/annurev.ph.38.030176.002033)

Hall M, Adin CA, Borin-Crivellenti S, Rudinsky A, Rajala-Schultz P, Lakritz J \& Gilor C 2015 Pharmacokinetics and pharmacodynamics of the glucagon-like peptide-1 analog liraglutide in healthy cats. Domestic Animal Endocrinology 51 114-121. (https://doi.org/10.1016/j. domaniend.2014.12.001)

Hansen LH, Abrahamsen N \& Nishimura E 1995 Glucagon receptor mRNA distribution in rat tissues. Peptides 16 1163-1166. (https://doi. org/10.1016/0196-9781(95)00078-X)

Hou L, Kongsted AH, Ghoreishi SM, Takhtsabzy TK, Friedrichsen M, Hellgren LI, Kadarmideen HN, Vaag A \& Nielsen MO 2013 Pre-and early-postnatal nutrition modify gene and protein expressions of muscle energy metabolism markers and phospholipid fatty acid composition in a muscle type specific manner in sheep. PLOS ONE $\mathbf{8}$ e65452. (https://doi.org/10.1371/journal.pone.0065452)

Jia Y, Cong R, Li R, Yang X, Sun Q, Parvizi N \& Zhao R 2012 Maternal low-protein diet induces gender-dependent changes in epigenetic regulation of the glucose-6-phosphatase gene in newborn piglet liver. Journal of Nutrition 142 1659-1665. (https://doi.org/10.3945/ jn.112.160341)

Jiang G \& Zhang BB 2003 Glucagon and regulation of glucose metabolism. American Journal of Physiology: Endocrinology and Metabolism 284 E671-E678. (https://doi.org/10.1152/ ajpendo.00492.2002)

Jiang Y, Cypess AM, Muse ED, Wu C, Unson CG, Merrifield RB \& Sakmar TP 2001 Glucagon receptor activates extracellular signalregulated protein kinase $1 / 2$ via cAMP-dependent protein kinase. PNAS 98 10102-10107. (https://doi.org/10.1073/pnas.131200398)

Khanal P, Husted SV, Axel AMD, Johnsen L, Pedersen KL, Mortensen MS, Kongsted AH \& Nielsen MO 2014 Late gestation over-and undernutrition predispose for visceral adiposity in response to a post-natal obesogenic diet, but with differential impacts on glucose- 
insulin adaptations during fasting in lambs. Acta Physiologica 210 110-126. (https://doi.org/10.1111/apha.12129)

Khanal P, Axel A, Kongsted A, Husted S, Johnsen L, Pandey D, Pedersen K, Birtwistle M, Markussen B \& Kadarmideen H 2015 Late gestation under-and overnutrition have differential impacts when combined with a post-natal obesogenic diet on glucose-lactate-insulin adaptations during metabolic challenges in adolescent sheep. Acta Physiologica 213 519-536. (https://doi.org/10.1111/apha.12391)

Kongsted AH, Tygesen M, Husted SV, Oliver M, Tolver A, Christensen VG, Nielsen JH \& Nielsen MO 2014 Programming of glucose-insulin homoeostasis: long-term consequences of pre-natal versus early post-natal nutrition insults. Evidence from a sheep model. Acta Physiologica 210 84-98. (https://doi.org/10.1111/apha.12080)

Kurland IJ \& Pilkis SJ 1995 Covalent control of 6-phosphofructo-2-kinase/ fructose-2, 6-bisphosphatase: insights into autoregulation of a bifunctional enzyme. Protein Science 4 1023-1037. (https://doi. org/10.1002/pro.5560040601)

MacDonald PE, De Marinis YZ, Ramracheya R, Salehi A, Ma X, Johnson PRV, Cox R, Eliasson L \& Rorsman P 2007 A K ATP channeldependent pathway within alpha cells regulates glucagon release from both rodent and human islets of langerhans. PLoS Biology 5 e143. (https://doi.org/10.1371/journal.pbio.0050143)

Manell H, Staaf J, Manukyan L, Kristinsson H, Cen J, Stenlid R, Ciba I, Forslund A \& Bergsten P 2016 Altered plasma levels of glucagon, GLP-1 and glicentin during OGTT in adolescents with obesity and type 2 diabetes. Journal of Clinical Endocrinology and Metabolism 101 1181-1189. (https://doi.org/10.1210/jc.2015-3885)

Marks V 1972 Glucagon. Clinics in Endocrinology and Metabolism 1 829-835. (https://doi.org/10.1016/S0300-595X(72)80045-8)

Nielsen MO, Kongsted AH, Thygesen M, Strathe AB, Caddy S, Quistorff B, Jørgensen W, Christensen VG, Husted S \& Chwalibog A 2013 Late gestation undernutrition can predispose for visceral adiposity by altering fat distribution patterns and increasing the preference for a high-fat diet in early postnatal life. British Journal of Nutrition 109 2098-2110. (https://doi.org/10.1017/S0007114512004199)

Olsen HL, Theander S, Bokvist K, Buschard K, Wollheim CB \& Gromada J 2005 Glucose stimulates glucagon release in single rat alpha-cells by mechanisms that mirror the stimulus-secretion coupling in beta-cells. Endocrinology 146 4861-4870. (https://doi.org/10.1210/en.2005-0800)

Quesada I, Tunduri E, Ripoll C \& Nadal A 2008 Physiology of the pancreatic a-cell and glucagon secretion: role in glucose homeostasis and diabetes. Journal of Endocrinology 199 5-19. (https://doi. org/10.1677/JOE-08-0290)

Reusens B \& Remacle C 2006 Programming of the endocrine pancreas by the early nutritional environment. International Journal of
Biochemistry and Cell Biology 38 913-922. (https://doi.org/10.1016/j. biocel.2005.10.012)

Rukkwamsuk T, Wensing T \& Geelen MJH 1999 Effect of fatty liver on hepatic gluconeogenesis in periparturient dairy cows. Journal of Dairy Science 82 500-505. (https://doi.org/10.3168/jds.S00220302(99)75260-4)

Safayi S, Theil PK, Hou L, Engbæk M, Nørgaard JV, Sejrsen K \& Nielsen MO 2010 Continuous lactation effects on mammary remodeling during late gestation and lactation in dairy goats. Journal of Dairy Science 93 203-217. (https://doi.org/10.3168/jds.2009-2507)

Sano H, Arai H, Takahashi A, Takahashi H \& Terashima Y 1999 Insulin and glucagon responses to intravenous injections of glucose, arginine and propionate in lactating cows and growing calves. Canadian Journal of Animal Science 79 309-314. (https://doi.org/10.4141/A98115)

Sundby F 1976 Species variations in the primary structure of glucagon. Metabolism 25 1319-1321. (https://doi.org/10.1016/S00260495(76)80132-1)

Sutherland C, O'Brien RM \& Granner DK 1996 New connections in the regulation of PEPCK gene expression by insulin. Philosophical Transactions of the Royal Society B, Biological Sciences 351 191-199. (https://doi.org/10.1098/rstb.1996.0016)

Taylor PD \& Poston L 2007 Developmental programming of obesity in mammals. Experimental Physiology 92 287-298. (https://doi. org/10.1113/expphysiol.2005.032854)

Unger RH 1971 Glucagon and the insulin: glucagon ratio in diabetes and other catabolic illnesses. Diabetes 20 834-838. (https://doi. org/10.2337/diab.20.12.834)

van Harten S, Brito R, Almeida AM, Scanlon T, Kilminster T, Milton J, Greeff J, Oldham C \& Cardoso LA 2013 Gene expression of regulatory enzymes involved in the intermediate metabolism of sheep subjected to feed restriction. Animal 7 439-445. (https://doi.org/10.1017/ S1751731112001589)

Vaughan M \& Steinberg GD 1963 Effect of hormones on lipolysis and esterification of free fatty acids during incubation of adipose tissue in vitro. Journal of Lipid Research 4 193-199.

Watanabe M, Hayasaki H, Tamayama T \& Shimada M 1998 Histologic distribution of insulin and glucagon receptors. Brazilian Journal of Medical and Biological Research 31 243-256. (https://doi.org/10.1590/ S0100-879X1998000200008)

Zhang L, Long NM, Hein SM, Ma Y, Nathanielsz PW \& Ford SP 2011 Maternal obesity in ewes results in reduced foetal pancreatic $\beta$-cell numbers in late gestation and decreased circulating insulin concentration at term. Domestic Animal Endocrinology 40 30-39. (https://doi.org/10.1016/j.domaniend.2010.08.004)

Received in final form 27 March 2018

Accepted 19 April 2018

Accepted Preprint published online 19 April 2018 